As to the colouring, most had brown hair and brown or grey eyes. Very few had dark hair, only two had red hair Several were described as having fair hair, but brown and dark brown greatly predominated. The colour of the eyes was noted as either dark, brown, hazel, grey, and blue. Brown hair with hazel or grey eyes greatly predominated, so also does this type normally in the London area; the dark Iberian-Mediterranean type being comparatively infrequent outside Cornwall.

1 Mental Diseases, 1883. ${ }^{2}$ Edinburgh Medical Journal, vol. x. ${ }^{3}$ Traite de a Folie des Femmes Enceintes. \& West Riding Asylum Reports, 1872 (To be continued.)

\section{A CASE OF TUMOUR OF THE CEREBRAL} CORTEX.

BY H. CECIL BARLOW, M.B.LOND., L.R.C.P., M.R.C.S., Farnborough.

THE following is a somewhat incomplete account of a case of tumour of the cerebral cortex, which is interesting in that several of the symptoms and physical signs which are diagnostic of that condition were absent.

History. - W. R, aged 57, an armourer sergeant, apparently in good health, was suddenly seized with convulsong and, rgor, which were confned to the left side of the body, beginning in and mainly affecting the face, but also the arm. During the attack $h$ as perfectiy conscious, but bat tween May ance.

Unfortunately I have been unable to obtain any account of his condition while there, but I have learned from his friends that he had one attack of convulsions.

State on Examination. - On the night of May 3 st I saw him for the first time. He was standing with head and shoulders bent forward-perfectly conscious, and appearing to understand all that was said to him, but he was vnable to articulate distinctly. There was frequent and marked spasm of the left facial muscles, and of the left arm, and to a less extent of the left leg. The mouth was open - tongue protruded, and saliva flowing from the mouth. The grasp of the left hand was decidedly weaker than that of the right. The deep reflexes were very brisk on the affected side. while sensation was markedly dulled and delayed to pain and touch on that side. The pulse-rate was 78 . He appeared free from pain The attack came on while in bed, and the twitching began in the face. He was put to bed. and a mixture of chloral and ammonium bromide adminis-
tered. There was no obtainable history of alcoholism, epilepsy, or specific disease.

Progress. - Next morning, June rst he appeared fairly comfortable having slept during the night, there was still marked twitching of the muscles of the left side of the face occurring every three or four minutes and very slight occasional spasm of the muscles of left arm. In the intervals between the spasms left facial palsy was obvious, and the left arm was decidedly weaker than the right. Temperature was normal, pulse 68, regular, good volume, moderate tension. There was no abnormal rigidity of the arterial walls. Sensation on the left side was dulled and delayed to touch and pain. An examination of the urine revealed nothing abnormal. Taste and smell were normal. Sight was good and the optic discs were normal. There was no discharge from the ears and no pain or tenderness of the head. The chest was emphysematous-the only abnormality discovered was a systolic bruit loudest at the aortic cartilage. He was ordered a liberal diet and given a mixture of bromide and potassium iodide (ten grains) three times a day. For the next four days, June 2nd, $3^{\text {rd, }}$, th and 5 th, the patient's general condition appeared to improve. The twitching gradually subsided, leaving marked facial palsy and paresis of the left arm and hand. The temperature was normal each day, and the pulse ranged between 68 and 76 . He slept comfortably at night. He complained of no pain, he was able to read his paper and converse with those about him. On June $3^{\text {rd }}$ there was a very decided increase of power in the left arm and hand, but no improvement in the face. He took his food well. On June 6th he began to be drowsy-the oromide was discontinued, but the iodide was still given-he complained of slight pain in the right parietal region. On June 7 th, 8th, gth, soth and the pain in the head passed off 0 on June 6 th, with the exception that the pain in the head passed off. On June 12 th he was more drowsy but he had no pain. The optic discs were examined and found normal. His pulse was pain, The optic discs were examined and found normal. His pulse was regular of good volume and tension, rate 68. Temperature without any preliminary coma, apparently from heart failure.

Necropsy. - I obtained leave to examine the brain. On removing the skull cap there was no abnormal appearance of the dura mater and no marked increase of tension. On exposing the brain marked injection of the vessels of the pia arachnoid over the right Rolandic area was evident. Just below the surface of the cortex, which was considerably softened for tumour the size and shape of a walnut. The main bulk of the tumour was situated in the lower portion of the ascending frontal lobe. Mr friend. Dr. Bertram Abrahams, has examined the tumour, and reports that it ir. Bertram Abrahams,

A consideration of the facts of the case would naturally lead to a diagnosis of a lesion in the right Rolandic area, but as to the nature of that lesion the data obtained did not give any very clear indication. The absence of optic neuritis, vomiting, and the very slight pain in the head all seemed to negative cerebral tumour. The short duration of the illness (thirty-three days) and the sudden termination without any preliminary stage of coma are points which are deserving of notice.

\section{MEMORANDA: \\ MEDICAL, SURGICAL, OBSTETRICAL, THERA- PEUTICAL, PATHOLOGICAL, ETc.}

THE TREATMENT OF INFLUENZA. IN the short paper in the BrITISH MEdical Journal of February 15 th I related a case of diabetes cured in a few weeks by measures exactly the opposite of those followed by the profession. 'This disease is a comparatively rare one. I now wish to speak of one of the most common and most fatal diseases of the period which may also be treated with success by methods the opposite of what are now ordinarily employed.

I allude to influenza. My first experience of influenza was in Aberdeen, when beginning my medical studies in the winter of 1836-7. The epidemic was almost universal, affecting more of the community than any I have met with since. Whole families were laid down and were absolutely helpless, and sometimes were discovered in this condition by their neighbours.

The last thing that was thought of in those days was to feed the sick, who wished for nothing, or to give them any stimulant whatever. They were absolutely left to Nature and I do not remember hearing of $a$ death during the whole epidemic ; it is quite possible that such may have occurred in old and feeble individuals, but I have no recollection of it; nor do I remember any epidemic occurring since with anything like the same severity or numbers. Common colds, which occur also in epidemics as being of a most infectious nature, got to be spoken of as influenza, but I am not aware of cases like those in Aberdeen occurring till the appearance of the severe form of the disease which originated in Russia and spread thence to this and other countries. The general method of treating disease had now completely altered, and with it the treatment of influenza. The toxic element, whatever it is, led as formerly to intense depression, but, instead of being left to Nature to be got rid of in its own way, was opposed by giving food and stimulants, both of which, especially the stimulants, stopped the natural actions of the system in expelling the poison, and in many cases led at once to a fatal result. The after-effects are too well known to need mention, and the deaths from them have been much more frequent after a more or less prolonged period than were those from the original attack. For myself I have all along treated cases of influenza on the old method of leaving them absolutely to Nature, and, so far as my memory goes, I do not remember the loss of a single case. Certainly for twenty-five years after my late colleague and successor joined me we did not lose a single case.

In Plea for a Simpler Life, and also in the preface to the conjoint volumes of Plea and Fads, I give numerous cases of patients who were cured when left to Nature, and of others which went wrong on the usual treatment of the day. Perhaps the most remarkable of the recoveries was that of an old lady of 87 , given fully at p. 87 of Plea. She has enjoyed the best of health ever since, and at the age of 94 she gives every promise of living her hundred years at least. On the other hand several cases which were treated wrongly from the beginning or were interfered with when making good progress to recovery are instances of the sad results daily occurring from what has come to be regarded by the profession as the proper method of treating the disease.

Diabetes and influenza are typical diseases which differ the one from the other as to their cause and treatment. Diabetes is the result of bad feeding and its cure is effected by a return to a more rational dietary.

In influenza an active poison has got into the system causing intense temporary depression which Nature if left free to 